(c) American Dairy Science Association, 2006.

\title{
Effects of Milking on Dairy Cow Gait
}

\author{
F. C. Flower, ${ }^{\star 1}$ D. J. Sanderson, $\dagger$ and D. M. Weary* \\ *Animal Welfare Program, Faculty of Food and Land Systems, and \\ †School of Human Kinetics, The University of British Columbia, Vancouver, Canada
}

\section{ABSTRACT}

We studied cows with $(\mathrm{n}=6)$ and without $(\mathrm{n}=26)$ sole ulcers before and after milking to explore how milking influences dairy cattle gait and how this differs for cows with hoof injuries. Video recordings of cows were digitized using motion-analysis software to calculate stride variables for each hoof. Gait was scored using a 1-to-5 numerical rating system ( $1=$ sound, $5=$ severely lame $)$ and a continuous 100-unit visual analog scale of gait attributes (back arch, head bob, tracking-up, and reluctance to bear weight). For cows with and without sole ulcers, differences in gait before and after milking were evident; after milking, all cows had significantly longer strides ( 123.3 vs. $133.5 \pm 2.0 \mathrm{~cm}$, respectively), higher stride height ( $8.3 \mathrm{vs} .8 .9 \pm 0.1 \mathrm{~cm}$ ), shorter stride durations ( 1.49 vs. $1.41 \pm 0.03 \mathrm{~s})$, walked faster ( 0.85 vs. 0.97 $\pm 0.03 \mathrm{~m} / \mathrm{s}$ ), and had shorter periods of triple support (3 legs in ground contact; 80.0 vs. $71.7 \pm 2.0 \%$ ). Trackingup and reluctance to bear weight improved after milking ( 20 vs. $16 \pm 2 ; 20$ vs. $15 \pm 1$, respectively), but numerical rating scores and back arch did not. Cows with sole ulcers walked differently than cows without for all measures, except swing duration, both before and after milking. Interactions between hoof health and milking were found for swing duration and head bob but when tested separately, the only effect was that cows without sole ulcers had longer swing durations before milking ( $0.45 \mathrm{vs} .0 .44 \pm 0.01 \mathrm{~s}$, respectively). Gait differences were probably due to udder distention and motivation to return to the home pen. Our results suggest that the most suitable time to assess lameness is after milking when differences between cows with and without ulcers are most evident.

Key words: cattle, gait, sole ulcer, milking

\section{INTRODUCTION}

With increases in the incidence of hoof and leg injuries and disease, research on dairy cattle lameness has grown considerably over the last $25 \mathrm{yr}$ (Clarkson et

Received November 15, 2005.

Accepted January 27, 2006.

${ }^{1}$ Corresponding author: fcf@interchange.ubc.ca al., 1996). Recent research has focused on improving methods of identifying subclinically lame cows (e.g., Flower et al., 2005), identifying which pathologies are painful (e.g., Whay et al., 1998), following the development of hoof pathologies over time (e.g., Webster, 2002), and understanding the risks factors for these pathologies (e.g., Bergsten, 2003).

Treating lameness, especially at the early stages, depends upon valid and reliable methods of identifying cows with hoof lesions. Recent studies have demonstrated that hoof pathologies can influence the way cows walk (Flower et al., 2005; Flower and Weary, 2006), but other factors may change gait, potentially affecting our ability to detect lame cows. For example, flooring features can alter gait: dairy cows have shorter strides on lower friction surfaces (Phillips and Morris, 2001), and longer strides on surfaces covered with manure slurry (Phillips and Morris, 2000).

Other cow features, such as physical conformation, may also affect gait. For example, Greenough et al. (1981) speculated that cows might swing their legs out while walking to avoid contact with a distended udder, although no research to date has tested how udder fill affects gait. Other studies on gait offer some insights. For example, horses prefer to trot at slower speeds when saddled with a heavy load (Wickler et al., 2001) and research on humans has found gait changes, such as shortening stride length, when subjects are carrying extra weight (Martin and Nelson, 1986; Pascoe et al., 1997). Therefore, it seems likely that cows with full, heavy udders will change their gait. In addition, the effects of painful hoof injuries and disease may be more pronounced when cows are walking with a full, heavy udder compared with after milking. Understanding these effects will provide a basis for recommending the most suitable times to conduct on-farm lameness assessments.

Traditionally, changes in gait are assessed using subjective gait-scoring methods (Manson and Leaver, 1988; Sprecher et al., 1997; Flower and Weary, 2006), but more recently researchers have begun using quantitative methods such as kinematic gait analysis, and force platforms (Rajkondawar et al., 2002; Van der Tol et al., 2002; Flower et al., 2005). The objectives of this experiment were to use both kinematic and subjective 
gait analysis to describe a) how cow gait changes after milking, and b) how these changes are affected by hoof pathologies, such as sole hemorrhages (SH) and sole ulcers (SU).

\section{MATERIALS AND METHODS}

\section{Cows and Management}

We studied 48 high-producing Holstein dairy cows in loose housing at the University of British Columbia's Dairy Education and Research Centre in Agassiz, Canada. Individuals were randomly selected from the herd, with the constraint that 24 were primiparous and 24 were multiparous cows. After hoof health assessment (see below), 8 cows with digital dermatitis were excluded and 2 animals were dropped for management reasons. The remaining primiparous $(\mathrm{n}=18)$ and multiparous cows (parity $=2$ to $7 ; \mathrm{n}=20$ ) differed in BCS (mean $\pm \mathrm{SD}, 3.1 \pm 0.3$ vs. $2.9 \pm 0.3 ; P<0.05$ ) and daily milk production $(28.7 \pm 4.3$ vs. $48.9 \pm 6.3 \mathrm{~kg} ; P<0.001)$, but not DIM (96 \pm 39 vs. $74 \pm 37 \mathrm{~d})$.

Cows were fed a TMR diet twice a day, formulated to meet or exceed requirements for lactating dairy cows (NRC, 2001). Water was freely available from self-filling troughs. Stalls were deep-bedded with $0.4 \mathrm{~m}$ of sand. Flooring within $1.85 \mathrm{~m}$ of the feed bunk was grooved $2.5-\mathrm{cm}$ thick rubber. Elsewhere in the pen, flooring was grooved concrete. Cows were milked in the parlor at 0500 and $1600 \mathrm{~h}$ daily. Cows were cared for according to the standards of the Canadian Council on Animal Care and a protocol approved by the University of British Columbia's Animal Care Committee.

\section{Data Collection}

To habituate cows to the filming conditions, animals were walked to and from the milking parlor daily for $4 \mathrm{wk}$ along a grooved concrete alley. A rope barrier in the alley forced cows to walk in a straight line in single file with minimal side-to-side movement. The cows were allocated to 2 groups for management purposes. The first group of 24 cows was filmed before and after morning milking (between 0510 and $0810 \mathrm{~h}$ ) for $7 \mathrm{~d}$ consecutively and then the procedure was repeated on the second group of 24 cows during the next $7 \mathrm{~d}$. Data collected in the current study and those of Flower et al. (2005) and Flower and Weary (2006) used the same cows, although the results reported in those earlier studies were only for cows walking from the parlor (i.e., after milking).

Kinematic Gait Analysis. Cows had one reflective marker, visible from all angles, wrapped around the entire circumference of each leg directly above the metacarpo- and metatarsophalangeal joints. The video recordings were digitized using PEAK Motus 7.1.1 (Peak Performance Technologies, Inc., Englewood, CO), and hoof-strike and toe-off events were defined visually from the video recordings by a single observer. Hoof strike occurred when the hoof first contacted the ground at the beginning of the stance phase. Toe-off occurred when the toe left the ground at the end of the stance phase. Basic kinematic measures (stride length, maximum stride height, stride duration, stance and swing durations, and hoof speed) were then calculated for each hoof as defined in Table 1. The proportions of double support (time with 2 hooves in ground contact) and triple support (time with 3 hooves in ground contact) during the gait cycle were calculated from stride and stance durations.

Subjective Gait Assessment. Using the same video recordings, a trained observer scored cow gait using a 1-to-5 numerical rating scoring system (NRS; where $1=$ sound and $5=$ severely lame) as outlined in detail in Flower and Weary, 2006), and an evaluation of 4 specific gait attributes (back arch, head bob, trackingup, and reluctance to bear weight) using a 100-unit continuous scale. Both ends of the scale had a description of the extreme forms of the condition. For example, degree of back arch had "flat" at one end (0) of the scale and "convex" at the other end (100), where "convex" represented the most extreme back arch the observer had seen in their experience. The observer recorded directly on a computer screen a position on the scale that represented the severity of the behavior observed. Each video recording was observed 9 times: twice for each of the 4 gait attributes, and once for the NRS.

Clinical Assessment of Hooves. Injuries to the corium, the highly vascularized tissue responsible for producing hoof horn tissue, are not immediately visible on the surface of the sole. Under normal conditions of hoof growth and wear, hemorrhages become visible approximately 8 to 10 wk after corium damage has occurred (Bergsten and Frank, 1996; Lischer and Ossent, 2000). Because we wished to understand how gait was affected by painful injuries, we recorded the presence of $\mathrm{SH}$ and SU 8 to 9 wk after the trial. To do this, a professional hoof trimmer trimmed the front and hind hooves of each cow and an experienced observer examined each hoof and recorded the presence of lesions using a modified version of Greenough and Vermunt's (1991) lesion scoring system. Number, location, and severity of lesions on each hoof were scored on a 4-point scale (1 = slight discoloration, 2 = moderate hemorrhagic lesion, $3=$ severe hemorrhagic lesion, $4=$ sole ulcer). At this time, we also noted the presence and location of digital dermatitis, both active (ulcerative or exudative lesions at the heel, with or without hair-like projections, painful to touch) and healed forms (dry, brown scabrous 
Table 1. Description of stride variables calculated from kinematic measurements

\begin{tabular}{ll}
\hline Variable & Description \\
\hline $\begin{array}{l}\text { Spatial } \\
\text { Stride length, cm } \\
\text { Maximum stride height, cm }\end{array}$ & $\begin{array}{l}\text { Horizontal displacement between } 2 \text { consecutive hoof strikes of the same hoof } \\
\text { Maximum vertical displacement between } 2 \text { consecutive hoof strikes of the same hoof }\end{array}$ \\
Temporal & Time interval between 2 consecutive hoof strikes of the same hoof \\
Stride duration, s & Time the hoof is in contact with the ground (interval between hoof strike and following toe off) \\
Stance duration, s & Time the hoof is not in contact with the ground (interval between toe off and following hoof strike) \\
Swing duration, s & Stride length/stride duration \\
Speed, m/s &
\end{tabular}

tissue, unresponsive to touch) and the presence of other foot pathologies, such as interdigital hyperplasia and interdigital necrobacillosis.

Hoof health data of 2 animals were not collected because these animals left the trial early; 1 had coliform mastitis and the other was dried off early for management reasons. Of the 46 cows examined, the majority had hoof pathologies (63\%) at the time of examination. No cases of interdigital hyperplasia, interdigital necrobacillosis, or healed digital dermatitis were recorded; however, the presence of active digital dermatitis was noted on 8 animals. Because we could not be certain whether digital dermatitis was present at the time of video recordings, these animals were deleted from the analysis. Six additional cows were deleted because there were fewer than $2 \mathrm{~d}$ of suitable video recordings that could be digitized or scored due to missing markers or animals stopping, stumbling, slipping, defecating, urinating, or performing any gait other than walking. The remaining 32 cows were grouped into 3 mutually exclusive hoof-health categories: healthy cows with no visible signs of injury or disease on hooves $(\mathrm{n}=15)$; cows having only $\mathrm{SH}(\mathrm{n}=11)$; and cows having SU and $\mathrm{SH}(\mathrm{n}=6)$.

\section{Statistical Analyses}

We calculated mean kinematic stride variables using the first stride on the video recording per day by averaging across the 4 hooves and $7 \mathrm{~d}$ of video recordings for each cow for each direction (before and after milking). Subjective gait assessment variables from each of the $7 \mathrm{~d}$ of recording were averaged to provide 1 value per cow per direction.

Previously, Flower et al. (2005) and Flower and Weary (2006) found no differences between SH and healthy animals. Therefore, we initially compared $\mathrm{SH}$ and healthy cows ( $1 \mathrm{df})$ using the GLM procedure of SAS (SAS Institute, 1985). For all variables, except reluctance to bear weight, no differences were found; therefore, $\mathrm{SH}$ and healthy cows were grouped as animals with no sole ulcers (nSU; $n=26)$. These variables were examined using the MIXED procedure of SAS to test the effect of hoof health (SU vs. nSU; $1 \mathrm{df}$ ), direction (before vs. after milking; $1 \mathrm{df}$ ), and the interaction between hoof health and direction ( $1 \mathrm{df}$ ), with cow as a random effect ( $30 \mathrm{df}$ ). For reluctance to bear weight, differences between the 3 hoof health groups were considered in an otherwise identical model. We ran PROC REG of SAS (30 df) separately for datasets before and after milking to describe the relationships among speed and the various temporal kinematic variables.

\section{RESULTS}

\section{Kinematic Gait Analysis}

On return to their home pen after milking, both nSU and SU cows had longer strides, higher stride height, shorter stride and stance durations, and walked faster than on their way to the milking parlor (Table 2). The proportion of triple support in the gait cycle dropped more than $6 \%$ after milking for both nSU and SU cows. Furthermore, cows with SU walked differently than cows without SU in all kinematic measures except for swing duration, both before and after milking: cows with SU walked with shorter strides, lower stride height, longer stride duration, longer stance duration, and walked more slowly than animals with nSU. An interaction between hoof health and milking was found for swing duration $(P<0.05)$. When SU and nSU cows were analyzed separately, animals with nSU had slightly longer swing durations before milking than after, but animals with SU showed no difference before and after milking.

Our findings for speed and the temporal variables (stride, stance, and swing durations, and triple support) should not be considered independent. When cows walked faster (speed), the time taken to complete a stride (stride duration) decreased $\left(R^{2}=-0.81\right)$. Stance duration $\left(R^{2}=0.97\right)$ and swing duration $\left(R^{2}=0.64\right)$ increased with increasing stride duration. A weaker negative correlation was found between speed and proportion of triple support $\left(\mathrm{R}^{2}=-0.31\right)$. In other words, as speed increased, less time was spent in with 3 hooves in ground contact. Values reported are for data after 
Table 2. Least squares means \pm SEM of basic kinematic stride variables before and after milking for cows with no sole ulcers $(\mathrm{nSU} ; \mathrm{n}=26)$ and cows with sole ulcers $(\mathrm{SU} ; \mathrm{n}=6$ )

\begin{tabular}{|c|c|c|c|c|c|c|c|}
\hline \multirow[b]{2}{*}{ Variable } & \multicolumn{2}{|c|}{$\mathrm{nSU}$} & \multicolumn{2}{|c|}{ SU } & \multicolumn{3}{|c|}{$P^{1}$} \\
\hline & Before & After & Before & After & M & $\mathrm{H}$ & $\mathrm{M} \times \mathrm{H}$ \\
\hline Stride length, cm & $126.3 \pm 1.7$ & $139.1 \pm 1.7$ & $120.5 \pm 3.6$ & $127.8 \pm 3.6$ & $<0.001$ & $<0.05$ & NS \\
\hline Stride height, $\mathrm{cm}$ & $8.6 \pm 0.2$ & $9.5 \pm 0.2$ & $7.9 \pm 0.3$ & $8.2 \pm 0.3$ & $<0.01$ & $<0.01$ & NS \\
\hline Stride duration, s & $1.42 \pm 0.03$ & $1.30 \pm 0.03$ & $1.55 \pm 0.06$ & $1.52 \pm 0.06$ & $<0.01$ & $<0.01$ & NS \\
\hline Stance duration, $\mathrm{s}$ & $0.97 \pm 0.02$ & $0.86 \pm 0.02$ & $1.12 \pm 0.05$ & $1.07 \pm 0.05$ & $<0.001$ & $<0.01$ & NS \\
\hline Swing duration, s & $0.45 \pm 0.01$ & $0.44 \pm 0.01$ & $0.43 \pm 0.01$ & $0.45 \pm 0.01$ & NS & NS & $<0.05$ \\
\hline Speed, m/s & $0.89 \pm 0.02$ & $1.08 \pm 0.02$ & $0.80 \pm 0.05$ & $0.87 \pm 0.05$ & $<0.001$ & $<0.01$ & NS \\
\hline Triple support, \% & $72.5 \pm 1.7$ & $65.9 \pm 1.7$ & $87.5 \pm 3.6$ & $77.4 \pm 3.6$ & $<0.001$ & $<0.001$ & NS \\
\hline
\end{tabular}

${ }^{1} P$-values for the effects of milking ( $\mathrm{M}=$ before vs. after milking), hoof health ( $\mathrm{H}=\mathrm{nSU}$ vs. $\left.\mathrm{SU}\right)$, and their interaction $(\mathrm{M} \times \mathrm{H})$.

milking, but very similar values were observed when analyzing the data from before milking.

\section{Subjective Gait Assessment}

Tracking-up improved after milking (Table 3), but no change was observed for NRS or back arch. Cows with SU had higher values for NRS, and walked with a more pronounced back arch and worse tracking-up compared with animals having nSU, both before and after milking. There was an interaction between hoof health and milking for head bob $(P<0.05)$; head bob slightly worsened for nSU cows, but improved for SU animals after milking. However, when nSU and SU groups were analyzed separately, the effect of milking was not significant.

The 3 hoof health groups differed in terms of reluctance to bear weight $(P<0.001$, Figure 1$)$. Cows with SU showed the greatest reluctance to bear weight when walking compared with healthy cows and cows with SH. This gait attribute improved after milking $(P<$ 0.001 ), with the greatest improvement seen in cows with SU (mean \pm SEM, $27 \pm 2$ vs. $19 \pm 2$ ). There was no evidence of an interaction between hoof health and milking.

\section{DISCUSSION}

To our knowledge, this study is the first to demonstrate that dairy cow gait changes after milking. For example, nSU cows had longer strides (1.39 vs. $1.26 \mathrm{~m}$ ) and shorter stride durations (1.30 vs. $1.42 \mathrm{~s}$ ), resulting in a faster walk ( $1.08 \mathrm{vs} .0 .89 \mathrm{~m} / \mathrm{s})$ after milking compared with before milking. These differences may be due to an increased motivation to walk after milking. All cows are likely to be motivated to return to their stalls and to fresh feed after milking, especially because cows tend to synchronize their feeding at this time (DeVries et al., 2003). Also, some cows may be fearful of the milking parlor (Rushen et al., 1999) and therefore, reluctant to walk in that direction. There is evidence to suggest that motivation to feed can suppress pain caused by lameness when chickens are food-deprived (Wylie and Gentle, 1998). Although cows in this study were not food-deprived, feeding motivation was likely high because both the availability and quality of feed improved after milking when fresh feed was provided; this increased feeding motivation may have suppressed pain-related behaviors to some extent. This study was not specifically designed to test walking motivation and

Table 3. Least squares means \pm SEM of subjective gait assessment before and after milking for cows with no sole ulcers ( $\mathrm{nSU} ; \mathrm{n}=26$ ) and cows with sole ulcers (SU; $\mathrm{n}=6$ )

\begin{tabular}{|c|c|c|c|c|c|c|c|}
\hline \multirow[b]{2}{*}{ Variable } & \multicolumn{2}{|c|}{$\mathrm{nSU}$} & \multicolumn{2}{|c|}{ SU } & \multicolumn{3}{|c|}{$P^{1}$} \\
\hline & Before & After & Before & After & M & $\mathrm{H}$ & $\mathrm{M} \times \mathrm{H}$ \\
\hline Numerical rating system ${ }^{2}$ & $3.4 \pm 0.1$ & $3.2 \pm 0.1$ & $3.8 \pm 0.1$ & $3.8 \pm 0.1$ & NS & $<0.01$ & NS \\
\hline Back $\operatorname{arch}^{3}$ & $22 \pm 2$ & $23 \pm 2$ & $39 \pm 5$ & $37 \pm 5$ & NS & $<0.01$ & NS \\
\hline Head bob ${ }^{3}$ & $2 \pm 1$ & $3 \pm 1$ & $6 \pm 2$ & $3 \pm 2$ & NS & NS & $<0.05$ \\
\hline Tracking up ${ }^{3}$ & $14 \pm 2$ & $8 \pm 2$ & $26 \pm 4$ & $24 \pm 4$ & $<0.01$ & $<0.01$ & NS \\
\hline
\end{tabular}

${ }^{1} P$-values for the effects of milking ( $\mathrm{M}=$ before vs. after milking), hoof health ( $\mathrm{H}=\mathrm{nSU}$ vs. SU), and their interaction $(\mathrm{M} \times \mathrm{H})$.

${ }^{2}$ Numerical rating system scored on a 5-point scale.

${ }^{3}$ Variables were scored on continuous 100 -unit visual analog scales. Both ends of the scale had a description of the extreme forms of the condition. For example, degree of back arch had "flat" at one end (0) of the scale and "convex" at the other end (100), where "convex" represented the most extreme back arch the observer had seen in their experience. 


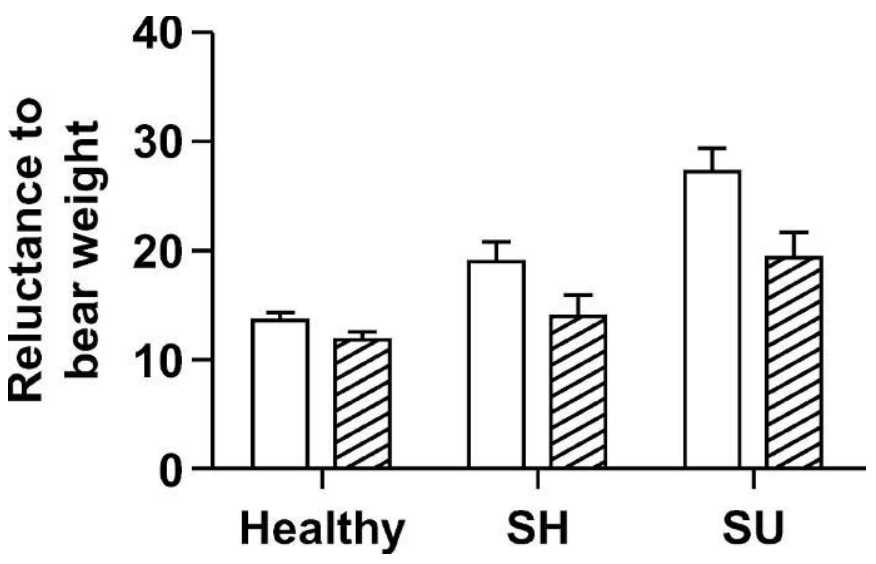

Figure 1. Least squares means $( \pm$ SEM) of reluctance to bear weight, scored using a 100-unit continuous scale, are shown for healthy cows ( $\mathrm{n}=15)$, cows with sole hemorrhages $(\mathrm{SH} ; \mathrm{n}=11)$, and cows with sole ulcers (SU; $\mathrm{n}=6$ ) before (empty bars) and after (shaded bars) milking.

future work is required to determine how motivation influences cow gait and the pain due to lameness.

Previous work on farm animals shows that differences in gait may result from differences in body conformation. For example, broiler chickens and turkeys, selected for large breast muscle and rapid growth rate, have a wider walking base and walk more slowly compared with birds with slower growth rates (Abourachid, 1991; Corr et al., 2003). Those studies concluded that gait differences resulted from a shift in the center of gravity due to the large breast muscle. Studies on conformation in cattle have focused on hoof conformation and its relationship to sole lesion development (Gitau et al., 1997; Offer et al., 2000), but little is known about other effects of body conformation in cattle. Only one study has examined how udder width and depth relate to subjective gait assessments, and found only weak correlations ( $\mathrm{r}=0.36$; Boelling and Pollott, 1998).

Studies in other species can provide some insight into how gait may change when carrying a heavy load. For example, Wickler et al. (2001) measured speed in trotting horses saddled with an $85-\mathrm{kg}$ weight vs. no load and found that horses with a load prefer to trot at slower speeds. Moreover, humans carrying a heavy backpack have shorter stride lengths (Pascoe et al., 1997), longer double-support times (2 feet in ground contact) and longer swing times (Martin and Nelson, 1986) than those carrying no load. Our findings were similar: slower speeds, shorter stride lengths, longer triple support times, and longer swing times when walking with a full udder (i.e., before milking). Daily milk production of cows in the current study averaged $38 \mathrm{~L} / \mathrm{d}$, so milk weight represented approximately $3 \%$ of a cow's BW per milking. In contrast, the studies on horses and humans cited above used relatively greater weights (15 to $20 \%$ of the subject's BW) carried on the subject's back. Although the load experienced by the cows in the current study was smaller, the positioning of this load (in this case between the hind legs) may increase its effect. Time in triple vs. double support is affected by walking speed; as observed in the current study, the faster a quadruped walks, the less time spent in triple support. Thus, these differences in the ratio of triple support could be due to cows walking more quickly when returning from milking. Indeed, all the kinematic variables are interrelated because they are all aspects of how each cow walks. Herlin and Drevemo (1997) were the first to report a negative correlation between speed and stride duration $\left(R^{2}=-0.30\right)$, and a positive correlation between stride and stance duration $\left(\mathrm{R}^{2}=0.31\right)$. We found similar, but stronger, relationships between these measures.

Stance durations of cows in this study were on average $0.16 \mathrm{~s}$ longer and swing durations $0.13 \mathrm{~s}$ shorter than those reported by Flower et al. (2005), resulting in an increase in time spent in triple support. The differences are likely due to differences in the way that stance and swing durations were calculated; toe-off (when the toe leaves the ground) was used to define the end of the stance phase in the current study vs. hoof-off (when the hoof first leaves the ground) in Flower et al. (2005).

Previous research has shown that cows with SU walk differently from healthy animals (Flower et al., 2005; Flower and Weary, 2006). The current study supports those findings; based on the NRS values, animals with SU had lower gait scores than cows with nSU. Furthermore, cows with SU had shorter strides, longer stride durations, walked more slowly, had a pronounced back arch and higher tracking-up compared with animals having nSU. Although there was no interaction between milking and hoof health, differences before and after milking were numerically for cows with nSU than for cows with SU. Animals with SU were likely to have adjusted their gait to minimize pain experienced during loading of the affected limb, and may have been unable to adjust their gait further in response to the extra weight from the milk and udder distension.

In conclusion, both the effect of milking and the effect of painful sole ulcers change the gait pattern of cows. Although most of the gait attributes did not show clear differences before and after milking, all the kinematic measures demonstrated a clear improvement and greater numerical difference between $\mathrm{nSU}$ and SU cows after milking. These results suggest that the most suitable time to conduct on-farm lameness assessments of dairy cattle is after milking. 


\section{ACKNOWLEDGMENTS}

We thank the faculty, staff, and students at University of British Columbia's Dairy Education and Research Centre and the University's Animal Welfare Program, especially Anne Marie de Passillé, Nelson Dinn, José Fregonesi, David Fraser, Jeff Rushen, Tim Shelford, and the late Jim Shelford for their help during the study. We thank Erin Bell for conducting hoof health examinations and Sarah Dumont for digitizing video recordings. The research was funded by the Natural Sciences and Engineering Research Council of Canada through the Industrial Research Chair in Animal Welfare, and by contributions from the BC Society for the Prevention of Cruelty to Animals, the BC Veterinary Medical Association, the Dairy Farmers of Canada, the Beef Cattle Industry Development Fund, the BC Dairy Foundation and many others listed at http:// www.landfood.ubc.ca/animalwelfare.

\section{REFERENCES}

Abourachid, A. 1991. Comparative gait analysis of two strains of turkey, Meleagris gallopavo. Br. Poult. Sci. 32:271-277.

Bergsten, C. 2003. Causes, risk factors, and prevention of laminitis and related claw lesions. Acta Vet. Scand. Suppl. 98:157-166.

Bergsten, C., and B. Frank. 1996. Sole haemorrhages in tied primiparous cows as an indicator of periparturient laminitis: effects of diet, flooring and season. Acta Vet. Scand. 37:383-394.

Boelling, D., and G. E. Pollott. 1998. Locomotion, lameness, hoof and leg traits in cattle I. Phenotypic influences and relationships. Livest. Prod. Sci. 54:193-203.

Clarkson, M. J., D. Y. Downham, W. B. Faull, J. W. Hughes, F. J. Manson, J. B. Merritt, R. D. Murray, W. B. Russell, J. E. Sutherst, and W. R. Ward. 1996. Incidence and prevalence of lameness in dairy cattle. Vet. Rec. 138:563-567.

Corr, S. A., M. J. Gentle, C. C. McCorquodale, and D. Bennett. 2003. The effect of morphology on walking ability in the modern broiler: A gait analysis study. Anim. Welf. 12:159-171.

DeVries, T. J., M. A. G. von Keyserlingk, and K. A. Beauchemin. 2003. Diurnal feeding pattern of lactating dairy cows. J. Dairy Sci. 86:4079-4082.

Flower, F. C., D. J. Sanderson, and D. M. Weary. 2005. Hoof pathologies influence kinematic measures of dairy cow gait. J. Dairy Sci. 88:3166-3173.

Flower, F. C., and D. M. Weary. 2006. Hoof pathologies influence subjective assessments of dairy cow gait. J. Dairy Sci. 89:139-146.

Gitau, T., S. M. Mbiuki, and J. J. McDermott. 1997. Assessment of bovine hoof conformation and its association with lameness, animal factors and management practices on small-scale dairy farms in Kiambu district, Kenya. Onderstepoort J. Vet. Res. $64: 135-140$
Greenough, P. R., F. J. MacCallum, and A. D. Weaver. 1981. Pages 52-53 in Lameness in Cattle. 2nd ed. John Wright and Sons, Bristol, UK.

Greenough, P. R., and J. J. Vermunt. 1991. Evaluation of subclinical laminitis in a dairy herd and observations on associated nutritional and management factors. Vet. Rec. 128:11-17.

Herlin, A. H., and S. Drevemo. 1997. Investigating locomotion of dairy cows by use of high speed cinematography. Equine Vet. J. Suppl. 23:106-109.

Lischer, C. J., and P. Ossent. 2000. Sole ulcers in dairy cattle-What's new about an old disease? Pages 46-48 in Proc. XI Int. Symp. Disorders Rumin. Digit, Parma, Italy.

Manson, F. J., and J. D. Leaver. 1988. The influence of concentrate amount on locomotion and clinical lameness in dairy cattle. Anim. Prod. 47:185-190.

Martin, P. E., and R. C. Nelson. 1986. The effect of carried loads on the walking patterns of men and women. Ergonomics 29:1191-1202.

NRC. 2001. Nutrient Requirements for Dairy Cattle. National Academy of Science. Washington, DC.

Offer, J. E., D. McNulty, and D. N. Logue. 2000. Observations of lameness, hoof conformation and development of lesions in dairy cattle over four lactations. Vet. Rec. 147:105-109.

Pascoe, D. D., D. E. Pascoe, Y. T. Wang, D. M. Shim, and C. K. Kim. 1997. Influence of carrying book bags on gait cycle and posture of youths. Ergonomics 40:631-641.

Phillips, C. J. C., and I. D. Morris. 2000. The locomotion of dairy cows on concrete floors that are dry, wet, or covered with a slurry of excreta. J. Dairy Sci. 83:1767-1772.

Phillips, C. J. C., and I. D. Morris. 2001. The locomotion of dairy cows on floor surfaces with different frictional properties. J. Dairy Sci. 84:623-628.

Rajkondawar, P. G., B. Erez, N. K. Neerchal, A. M. Lefcourt, R. M. Dyer, M. A. Varner, and U. Tasch. 2002. The development of an objective lameness scoring system for dairy herds: Pilot study. Trans. ASAE 45:1123-1125.

Rushen, J., A. M. B. de Passillé, and L. Munksgaard. 1999. Fear of people by cows and effects on milk yield, behavior, and heart rate at milking. J. Dairy Sci. 82:720-727.

SAS Institute. 1985. SAS User's Guide. Statistics. Version 5 ed. SAS Inst., Inc., Cary, NC.

Sprecher, D. J., D. E. Hostetler, and J. B. Kaneene. 1997. A lameness scoring system that uses posture and gait to predict dairy cattle reproductive performance. Theriogenology 47:1179-1187.

Van der Tol, P. P. J., J. H. M. Metz, E. N. Noordhuizen-Stassen, W. Back, C. R. Braam, and W. Weijs. 2002. The pressure distribution under the bovine claw during square standing on a flat substrate. J. Dairy Sci. 85:1476-1481.

Webster, A. J. F. 2002. Effects of housing practices on the development of foot lesions in dairy heifers in early lactation. Vet. Rec. 151:9-12.

Whay, H. R., A. E. Waterman, A. J. F. Webster, and J. K. O’Brien. 1998. The influence of lesion type on the duration of hyperalgesia associated with hindlimb lameness in dairy cattle. Vet. J. 156:23-29.

Wickler, S. J., D. F. Hoyt, E. A. Cogger, and K. M. Hall. 2001. Effect of load on preferred speed and cost of transport. J. Appl. Physiol. 90:1548-1551.

Wylie, L. M., and M. J. Gentle. 1998. Feeding-induced tonic pain suppression in the chicken: Reversal by naloxone. Physiol. Behav. 64:27-30. 